\title{
Sentimentos de pais de crianças acidentadas em automóveis sem uso de assento de segurança infantil
}

The feelings of parents of children victims of accidents in automobiles without child restraint systems

Sentimientos de padres de niños accidentados en automóviles sin utilizar el asiento de seguridad infantil

Rosangela Martins Ferreira ${ }^{1}$, Maria Dalva de Barros Carvalho²

${ }^{1}$ Enfermeira. Discente do Programa de Pós-Graduação em Enfermagem, nível Mestrado, da Universidade Estadual de Maringá (UEM). Maringá, PR, Brasil. E-mail: ro enfer@yahoo.com.br.

${ }^{2}$ Enfermeira, Doutora em Enfermagem. Professora Associada da UEM. Maringá, PR, Brasil. E-mail: mdbcarvalho@uem.com.br.

\section{RESUMO}

Os acidentes se configuram em um problema de saúde pública no Brasil. O objetivo deste estudo foi compreender a experiência de pais de crianças vítimas de acidentes automobilísticos sem a utilização de Assento de Segurança Infantil (ASI) ocorridos em Londrina, Paraná, de 2008 a 2011. Estudo exploratório de abordagem qualitativa. Os participantes foram 17 pais de crianças de zero a oito anos, atendidas pelo Sistema Integrado de Atendimento ao Trauma de Emergência (SIATE) e encaminhadas a hospitais. A análise dos dados se deu através da análise de conteúdo, resultando em duas categorias: Acidente de trânsito: quem está a salvo?; Sentimentos no momento do acidente. Concluiu-se que as pessoas não acreditam que acidentes possam acontecer consigo ou com pessoas próximas. Sentimentos de nervosismo são os observados no momento do acidente. A educação se mostra como ponto de partida para o uso do ASI, daí a importância do enfermeiro como profissional educador. Descritores: Assentos de Segurança Infantil; Acidentes de Trânsito; Enfermagem; Criança.

\section{ABSTRACT}

Accidents are a public health problem in Brazil. The objective of this study was to understand the experience of parents of children victims of automobile accidents without a child restraint systems (CRS) taken place in Londrina, Paraná, from 2008 to 2011. This exploratory study was performed with a qualitative approach. The participants were 17 parents of children of ages zero to eight years, seen by the Integrated Emergency Trauma Care Service and referred to hospitals. The data analysis was performed using content analysis, which revealed two categories: Traffic accidents: who is safe?; Feelings at the time of the accident. In conclusion, people do not believe that accidents may happen with them or with close ones. Feelings of nervousness are observed at the time of the accident. Education is a starting point for using the CRS, thus the importance of nurses as educators.

Descriptors: Child Restraint Systems; Accidents, Traffic; Nursing; Child.

\section{RESUMEN}

Los accidentes constituyen un problema de salud pública en Brasil. Se objetivó comprender la experiencia de padres de niños víctimas de accidentes automovilísticos sin utilización de Asiento de Seguridad Infantil (ASI) sucedidos en Londrina-PA, de 2008 a 2011. Estudio exploratorio de abordaje cualitativo. Participaron 17 padres de niños de 0 a 8 años, atendidos por el Sistema Integrado de Atención del Trauma de Emergencia (SIATE) y derivados a hospitales. Datos analizados por análisis de contenido, resultando dos categorías: "Accidente de tránsito, ¿quién está a salvo?"; "Sentimientos al momento del accidente”. Se concluye en que las personas no creen que puedan ocurrir accidentes a sí mismos o a personas próximas. Se observan sentimientos de nerviosismo al momento del accidente. La educación se muestra como punto de partida para el uso del ASI, de allí la importancia del enfermero como educador.

Descriptores: Sistemas de Sujeción Infantil; Accidentes de Tránsito; Enfermería; Niño. 


\section{INTRODUÇÃO}

Os acidentes de trânsito, assim como as demais causas externas, se tornaram ao longo dos anos um importante problema de saúde pública no Brasil e têm provocado forte impacto na morbimortalidade da população. A relevância econômica destas causas pode ser medida em valores ao se verificar os gastos hospitalares com internação nestes casos.

Estima-se que o custo total do atendimento às vítimas de causas externas pelo sistema público de saúde em 2004 teria sido de $R \$ 2,2$ bilhões; o das agressões, de R\$119 milhões; e dos acidentes de trânsito, de 453 milhões de reais. Esse conjunto de gastos equivaleria a cerca de $4 \%$ dos gastos totais com a saúde pública naquele ano(1).

Dados do Ministério da Saúde e do Ministério das Cidades registraram em 2008, a ocorrência de aproximadamente 39 mil óbitos e 619 mil vítimas nãofatais, muitos com sequelas irreversíveis, decorrentes de acidentes de trânsito(2).

A cada morte no trânsito estimam-se outros 20 acidentados que ficam feridos, muitos com sequelas irreversíveis, exigindo um esforço brutal do setor de saúde e das famílias brasileiras. As famílias atingidas não se restringem as dos próprios acidentados, mas alcançam também todas as outras que recorrem aos hospitais públicos, em função de outras doenças e que ficam à espera de atendimento(3).

Estima-se que se nada for feito, as mortes no trânsito chegarão a 1,9 milhões, em 2020, saltando da atual nona para a quinta causa de mortes no planeta até 2030. Esta projeção está diretamente relacionada ao aumento dos índices de motorização dos países pobres e emergentes, sem equivalente investimento na segurança viária(3).

Diante de números tão expressivos de mortes, há um grupo que merece destaque por sua vulnerabilidade: as crianças. Elas estão expostas a diversos agravos e, por não saberem cuidar de si, dependem de outros que resguardem sua segurança. No caso do transporte em veículos automotivos, a melhor opção para preservar sua integridade é a utilização de um assento de segurança infantil (ASI) adequado.

Com a implantação do Código Brasileiro de Trânsito (CBT) passou a ser obrigatório o uso dos ASI, porém, não foram especificadas as características destes equipamentos $^{(4)}$. Somente em 2008 foi editada a
Resolução n 277 pelo Conselho Nacional de Trânsito (Contran) ${ }^{(5)}$, definindo os diferentes equipamentos para o transporte de crianças: bebê conforto, cadeirinhas, assento elevatório e cinto de segurança. Esta resolução prevê um acompanhamento sobre sua aplicação, seus benefícios, bem como sugestões para o aperfeiçoamento das medidas adotadas.

Diante deste processo de formação de um novo perfil brasileiro, voltado à prevenção de agravos infantis em acidentes de trânsito, torna-se necessário também disponibilizar maior conhecimento às autoridades e à população, a fim de possibilitar embasamento teórico para estabelecer estratégias que melhorem a segurança das crianças.

Mesmo diante de tamanha relevância a ser dispensada aos acidentes de trânsito, principalmente no que se refere às crianças, ainda há espaço para produção científica desta temática no cenário nacional, devido ser uma lei recentemente promulgada no Brasil. Daí a importância de estudos do tipo exploratório como este, em que se busca compreender a experiência de atores em situações pontuais, de modo que a divulgação destas informações possam subsidiar outros estudos e atividades de prevenção. Diante disso, o objetivo do estudo foi compreender a experiência de pais de crianças vítimas de acidentes automobilísticos sem uso de assento de segurança infantil na cidade de Londrina-PR.

\section{METODOLOGIA}

Estudo exploratório de abordagem qualitativa. Os participantes do estudo foram pais de crianças de zero a oito anos, residentes em Londrina, que sofreram acidente de automóvel nas vias urbanas na cidade, foram atendidas pelo Sistema Integrado de Atendimento ao Trauma de Emergência (Siate), encaminhadas aos hospitais do município no período de janeiro de 2008 a junho de 2011, e que após contato telefônico aceitaram participar do estudo.

O acesso à fonte de informações sobre os sujeitos se deu por meio da utilização do banco de dados de ocorrência do Corpo de Bombeiros, disponível on-line no site http://www.bombeiroscascavel.com.br/. As informações de ocorrências geradas pelo site foram analisadas, de modo a extrair os dados necessários para identificar os hospitais para os quais as crianças foram encaminhadas pelo Siate. Foram coletadas informações 
que permitissem localizar estes menores nos arquivos de prontuários hospitalares.

Os hospitais que permitiram localizar os dados por meio dos prontuários incluíram três públicos e um filantrópico. Todos eles foram contatados e comunicados formalmente acerca do interesse de realização da pesquisa em seus prontuários. Na sequência, o projeto foi submetido à apreciação da Comissão de Bioética e Ética do Hospital Filantrópico, obtendo parecer favorável (n०.042/10).

A busca aos prontuários teve como objetivo coletar o número do telefone e endereço dos pais das crianças. No primeiro momento, foi realizado o contato telefônico junto a todas as famílias que possuíam o número cadastrado nos hospitais. O contato pessoal era realizado após o insucesso na busca telefônica.

Esclarecidos os objetivos do estudo, sua importância e demais dúvidas dos entrevistados, o Termo de Consentimento Livre e Esclarecido (TCLE) fornecido pelo pesquisador, era então lido e assinado individualmente, garantindo o anonimato do sujeito e a utilização dos dados apenas para os fins de desenvolvimento do estudo.

No momento da entrevista, foi utilizada a pergunta orientadora: "O que foi para o (a) senhor (a) a experiência de ter um filho envolvido em um acidente de automóvel sem utilizar o Assento de Segurança Infantil?" As entrevistas foram gravadas na íntegra, com auxílio de um gravador digital.

Após a realização das entrevistas, estas foram transcritas na íntegra. A análise dos dados foi realizada por meio de Análise de Conteúdo, expressão comumente usada para representar o tratamento do teor de uma pesquisa qualitativa ${ }^{(6)}$. As entrevistas foram analisadas através da leitura excessiva de todo material, e a partir da interpretação e agrupamento dos dados, as categorias começaram a emergir aos olhos das pesquisadoras. Os sujeitos foram identificados com uma letra e um número, a letra $M$ se refere à entrevista realizada com mãe, e a letra $\mathrm{P}$ com pai, os números referem-se à sequência em que as entrevistas foram realizadas.

\section{RESULTADOS E DISCUSSÃO}

A pesquisa envolveu a participação de um total de 17 pais (em três famílias participaram pai e mãe, nas demais, apenas um membro). Deste total, quatro declararam que o filho utilizava ASI no momento do acidente, um pai declarou utilizar o cinto de segurança adequadamente. Portanto, a experiência de nove famílias (11 pais) cujos filhos não usavam o ASI será analisada pela exposição e discussão de seus relatos.

Dos 11 pais, distribuídos em nove famílias, e suas vivências a serem discutidas, quatro deles já haviam adquirido o ASI para seu filho na data do acidente, porém não o utilizava no momento do evento ou utilizava de maneira inadequada, porém, os depoimentos serão apresentados em conjunto. Depois das transcrições de todas as entrevistas, e após a leitura em profundidade de cada uma delas, emergiram duas categorias: Acidente de trânsito: quem está a salvo?; Sentimentos no momento do acidente.

\section{Acidente de trânsito: quem está a salvo?}

Os acidentes automobilísticos comumente são associados à ideia de viagem, de modo que as pessoas costumam relacionar este evento a algo distante de seu cotidiano, e não como algo que possa acontecer nos percursos comumente trafegados. De modo similar, tal ideia leva a um comportamento para buscar proteção apenas naquelas situações pontuais, fora do dia a dia. Isto se aplica ao uso do ASI. Os discursos dos sujeitos enfatizam isso:

[...] a gente foi viajar, dai eu falei pra ele que tinha que comprar o tal do assento, porque não dava pra pegar a estrada sem [...]. (M06)

[...] a gente pensa só assim, não... precisa da cadeirinha quando eu vou viajar, mas não é só na viagem, só na estrada né, na cidade as vezes acontece as coisas também [...]. (M12)

A relação do acidente com a viagem, com longa distância é tão comum que podemos visualizar em publicações científicas a recomendação de que “maximizar o uso de dispositivos de contenção adequados é fundamental e essencial para proteger toda criança em toda viagem"(7).

A lista de prioridades no transporte de crianças seguras para fazer tal inferência preconiza: 1) use um dispositivo de contenção em toda viagem; 2) mantenha as crianças com menos de 13 anos de idade no banco traseiro do veículo; 3) use o dispositivo de contenção 
apropriado à idade e ao tamanho da criança; e 4) use o dispositivo de contenção corretamente ${ }^{(8)}$.

Nota-se a prioridade dada a viagens, porém acidentes de transporte não ocorrem apenas longe do domicílio. Um aspecto relevante extraído das falas dos pais se refere ao fato do acidente ter acontecido quando eles menos esperavam, ou seja, nas proximidades da sua residência, ou durante trajetos diários, em percursos bem conhecidos pelos motoristas. Observa-se nas seguintes expressões:

\section{[...] tava chegando pertinho mesmo, já tava aqui na avenida [...]. (M02)}

[...] eu tava levando eles aqui na minha mãe, que é na avenida ali, só que a gente assim na hora, pertinho assim a gente não se preocupa, acha que nunca vai acontecer, $e$ aconteceu bem ali pertinho[...]. (M11)

Dificilmente alguém pensa em acidente como algo possível de acontecer consigo ou alguém próximo, relaciona-o sempre com um evento distante. Alguns fatores são enumerados como influência ao comportamento do motorista, entre eles a estimativa de risco, que é o medo de consequências adversas ${ }^{(9)}$.

Os indivíduos, de forma geral, sabem que ocorrem muitas mortes no trânsito, mas o que predomina é a sensação de que "nunca vai acontecer comigo". Esta sensação deve-se à diferença entre as percepções do risco coletivo e do risco individual. De fato, na perspectiva do indivíduo, uma morte no trânsito é um evento muito raro para causar preocupação, o que contribui para um comportamento otimista ${ }^{(9)}$, como é possível observar nos seguintes depoimentos:

[...] nunca vai acontecer com a gente né, nunca imaginei, aquele dia, eu indo trabalhar[...]. (M11)

[...] a gente acha que nunca vai acontecer, por mais que anda nesse trânsito e vê acidente, pensa é ali né, nunca vai ser com a gente [...]. (M12)

Outro aspecto que merece destaque é o fato de que as ocorrências violentas no trânsito são vistas pela maioria das pessoas como uma fatalidade, enquanto que na realidade, grande parte delas decorre de omissões quanto à manutenção de estradas e via públicas, às condições dos veículos, à fiscalização(10).
É possível que, em função deste tipo de concepção, de que "comigo nunca vai acontecer", é que seja dispensada tão pouca importância à prevenção de acidentes. Se cada um destes pais estivesse esperando que o acidente pudesse ocorrer a qualquer momento consigo e com aqueles que transportavam na ocasião, as consequências certamente seriam muito menores quando comparadas às ocorridas, pois por menos grave que seja o acidente é um momento de muita tensão, como será discutido na categoria subsequente.

\section{Os sentimentos no momento do acidente}

O momento do acidente é único para cada indivíduo, bem como as experiências que levadas desse acontecimento, por ser um evento inesperado não há como se prever ou ensaiar ações e reações.

Alguns pais relataram os sentimentos vivenciados neste episódio, o que possibilitou observar o quão significativo foi este evento para a vida de cada um deles, até mesmo porque quando questionados, em relação ao que cada um lembrava-se do dia do acidente, emanaram relatos ricos em detalhes e carregados de emoção, como é possível perceber nas falas que se seguem:

[...] não sentia minhas pernas... você não tem ideia do nervoso que a gente fica, enquanto não vê que tá todo mundo bem, enquanto não pega, não tem certeza [...]. (M06)

[...] você entra em transe na hora, eu mesmo assim parei, na hora eu achei que ia morrer [...]. (M02)

[...] fui ligar para o meu marido e quem disse que eu lembrava o número dele?[...]. (M12)

Percebe-se nos discursos que, até mesmo funções simples, como a de pegar o telefone e discar o número de algum familiar, os pais ficavam comprometidos pelo estado de forte tensão provocado pelo acidente. Este comportamento foi constatado, principalmente, nos casos em que era a mãe da criança a condutora do automóvel e esta se encontrava desacompanhada.

As lembranças do dia do acidente são sempre muito claras, posto que as imagens gravadas nos eventos traumáticos se inscrevem como uma queimadura na memória das vítimas e permanecem circulando indiscriminadamente nas vias cognitivas ${ }^{(11)}$. 
Mesmo não sendo a intenção de este estudo avaliar de quem seria a responsabilidade pelo acidente, alguns relatos ressaltaram que a mesma era de um terceiro, no caso daquele que conduzia o veículo que colidiu com o do entrevistado. Um dos motivos do entrevistado em abordar esta temática, definindo a culpa ou responsabilidade do acidente pode ser atribuído à indignação experimentada por estes sujeitos, por estar trafegando corretamente, obedecendo às leis e, de repente, por irresponsabilidade, ou descuido de outrem, se percebe vivenciando uma situação como aquela:

[...] o motorista do outro carro era menor de idade [...]. (M14)

[...] ia subindo ali, um carro atravessou a preferencial [...]. (M11)

[...] ele furou o sinal vermelho... ele tava alcoolizado, tinha bebido [...]. (M04)

[...] quando a gente viu o carro entrou com tudo na nossa frente [...] ele tava caindo de bêbado [...]. (M02)

Os pais admitiram que não estavam utilizando o equipamento de proteção para seu filho, porém enfatizaram que a culpa do acidente não foi deles, pois trafegavam adequadamente e a ocorrência do acidente foi pelo erro de outra pessoa. Essa necessidade de pensar que eles não eram os responsáveis pelo evento, pode estar relacionada à necessidade de buscar reduzir um eventual sentimento de culpa, justificando possíveis consequências do acidente para si ou para alguém de sua família. Tal mecanismo de transferência de culpa percebese de maneira inconsciente pelos entrevistados.

Estudo realizado a fim de verificar o fator humano como risco para acidentes ${ }^{(12)}$ destaca o depoimento de um policial de trânsito que afirmou que os condutores sempre tentam justificar os acidentes, nunca reconhecendo o fato de não adaptarem seu comportamento às condições da via ou do veículo.

O bem material é relevante ao se pensar em acidentes de trânsito, afinal o valor de um carro ou do seu conserto tem um peso único para cada família, e os impactos deste evento devem levar em conta seus valores morais, situação financeira, estrutura e relação familiar, entre outros fatores. Nesse sentido, houve quem demonstrasse esta preocupação no momento do acidente:
[...] danificou demais o carro, quase que deu perda total, a sorte é que a gente tinha seguro [...]. (M12)

[...] dai a hora que eu vi ele (esposo), me desesperei, comecei a chorar, porque a gente bate né, o carro é dele, e ele: "amor, não pensa nisso agora [...]. (M12)

Entretanto, alguns entrevistados revelaram que este aspecto deveria ser o último a ser lembrado e discutido, e que as pessoas que ocupavam os carros é que mereciam maior atenção e preocupação:

[...] se tivesse acontecido alguma coisa grave, só arrumar a Brasilia não ia trazer a vida da minha filha [...]. (M04)

[...] ele só pensou no carro, não pensou no meu filho né, eu tava preocupada com o mais importante e ele preocupado com uma lata, com uma pedaço de lata né, um pedaço de lata velha que a gente usa mas que não é tão importante como a vida de uma criança [...]. (M02)

Todavia, segundo alguns relatos, houve, por parte da terceira pessoa envolvida no acidente uma preocupação com os danos materiais. Рara os pais das crianças, esta atitude foi considerada como sendo extremamente agressiva, passando a impressão de que o motorista provocara um acidente, sem se importar com as pessoas que ocupavam o outro veículo. Tal atitude de insensibilidade, e que chocou os depoentes parece ocorrer com certa frequência em situações desta natureza.

Diante de uma observação empírica, nota-se que a preocupação com valores materiais está diretamente ligada à situação financeira das famílias entrevistadas. Ao realizar as entrevistas foi possível visualizar que a maioria das famílias residia em casas humildes e o carro envolvido no acidente era do tipo popular. Fator este que pode influenciar não uso do ASI, visto que além do nível cultural para compreender a importância de seu uso é necessário a compra do equipamento, já que não é item obrigatório nos veículos.

Estes fatores influenciam não somente no uso do ASI como também no uso correto do equipamento. Estudo realizado em Maringá-PR(13) verificou que erros de uso foram influenciados pela presença de várias crianças no veículo, nível de escolaridade e renda dos pais, semelhantes aos fatores encontrados nos EUA ${ }^{(14)}$. 


\section{CONCLUSÃO}

Os números de vítimas de acidentes de trânsito no Brasil aumentam a cada dia. Diante de estatísticas tão expressivas deste agravo, torna-se cada vez mais necessário realizar pesquisas sobre a temática, não apenas para demonstrar a gravidade deste acontecimento, já expressa em números, mas também no intuito de desvelar tais experiências a partir da perspectiva dos envolvidos, com vistas a difundir formação que subsidiem a prevenção de futuras ocorrências. Diante disso, ressalta-se a relevância deste estudo exploratório.

Como verificado em grande parte dos depoimentos, as pessoas não acreditam que acidentes possam acontecer consigo ou com pessoas que lhes são próximas. A ideia prevalente é a de que se trata de um evento distante; o que faz com que a segurança seja colocada em segundo plano. O ideal não é que as pessoas sempre estejam aguardando o acidente ocorrer, mas que tenham a consciência de que isso pode acontecer e que priorizem ações preventivas quanto à segurança, dentre elas a utilização do ASI.

É natural que os sentimentos no momento do acidente se relacionem com nervosismo, pela surpresa

\section{REFERÊNCIAS}

1. Rodrigues RI, Cerqueira DRC, Lobão WJA, Carvalho AXY. Os custos da violência para o sistema público de saúde no Brasil: informações disponíveis e possibilidades de estimação. Cad Saude Publica [Internet]. 2009 [acesso em: 30 jun 2013];25(1):29-36. Disponível em:

http://dx.doi.org/10.1590/S0102-311X2009000100003. 2. Organización Mundial de la Salud. Informe mundial sobre prevención de los traumatismos causados por el tránsito: resumen [Internet]. Washington: OMS; 2004 [acesso em: 30 jun 2013]. Disponível em:

http://www.who.int/violence_injury_prevention/publications/ro ad traffic/world report/summary es.pdf.

3. Portal da Saúde [Internet]. Brasília: Ministério da Saúde; 2010 [acesso em: 30 jun 2013]. Década de Ação para a Segurança no Trânsito 2011-2020. Disponível em:

http://portal.saude.gov.br/portal/saude/profissional/visualizar texto.cfm?idtxt=37121.

4. Ministério das Cidades. Código de Trânsito Brasileiro

[Internet]. $3^{a}$ ed. Brasília: DENATRAN; 2008 [acesso em: 30 jun 2013]. Disponível em:

http://www.denatran.gov.br/publicacoes/download/ctb.pdf. 5. Resolução $n^{\circ} 277$, de 28 de maio de 2008 (BR). Dispõe sobre o transporte de menores de 10 anos e a utilização do dispositivo de retenção para o transporte de crianças em veículos. Diário Oficial da União (Brasília). 2008 Jun 09 [acesso em: 30 jun 2013]. Disponivel em:

http://www.denatran.gov.br/download/Resolucoes/RESOLUCA O CONTRAN 277.pdf. frente à situação inesperada, e também com o medo, por inexperiência em circunstâncias deste tipo. A transferência da responsabilidade do acidente para outra pessoa se apresentou como forma de minimizar uma eventual sensação de culpa dos pais, principalmente pelo fato dos mesmos estarem expostos a um julgamento em função da não utilização do ASI. Este julgamento, em geral, provém dos próprios familiares, dos profissionais que atenderam à ocorrência ou mesmo da sociedade.

A partir dos relatos dos pais de crianças acidentadas sem utilização do ASI, verifica-se que a maioria deles relata que nunca imaginava que o acidente pudesse acontecer. Deste modo são importantes depoimentos como estes, por serem capazes de sensibilizar outros pais e de motivar uma mudança de conduta baseada na dor do outro.

O enfermeiro como profissional educador tem a responsabilidade de transmitir vivências como as relatadas neste estudo, para outros pais, não a fim de educar baseando-se no medo, mas de utilizar-se de uma experiência real para que outros não cometam os mesmos erros e venham sofrer a mesma dor.

6. Minayo MC. O desafio do conhecimento: pesquisa qualitativa em saúde. São Paulo: Hucitec; 2008.

7. Zonfrillo MR, Durbin DR, Winston FK. Child passenger safety: protecting your patients on every trip. J Pediatr (Rio J)

[Internet]. 2012 [acesso em: 30 jun 2013];88(4):283-5. Disponível em: http://dx.doi.org/10.2223/JPED.2209.

8. Committee on Injury, Violence and Poison Prevention. Child Passenger Safety. Pediatrics [Internet]. 2011 [acesso em: 30 jun 2013];127(4):e1050-66. Disponível em:

http://dx.doi.org/10.1542/peds.2011-0215.

9. Evans L. Traffic Safety. Bloomfield Hills: Science Serving Society; 2004.

10. Cocco M, Lopes MJM, Peretto M. Violência e acidentes: concepções de jovens vítimas desses agravos. Ciênc. cuid. saúde. [Internet]. 2009 [acesso em: 30 jun 2013];8(2):228-35. Disponivel em:

http://dx.doi.org/10.4025/cienccuidsaude.v8i2.8203.

11. Bringhenti ME, Luft CB, Oliveira WF. Transtorno do estresse pós-traumático entre vítimas de acidentes de trânsito. PsicoUSF (Impr.) [Internet]. 2010 [acesso em: 30 jun 2013];15(2):193203. Disponível em: http://dx.doi.org/10.1590/S141382712010000200007.

12. Bottesini G; Nodari CT. O fator humano nos acidentes rodoviários: motivos e possíveis soluções levantados em um grupo focado. In: Anais do $22^{\circ}$ Congresso de Pesquisa e Ensino em Transportes [Internet]; 2008; Porto Alegre; Brasil. Porto Alegre: UFRGS; 2008 [acesso em: 30 jun 2013]. Disponível em: http://www.cbtu.gov.br/monografia/2009/trabalhos/artigos/en genharia/1 348 AC.pdf. 
13. Oliveira SR, Leone C, Carvalho MD, Santana RG, Lüders LE, Oliveira FC. Child safety seat usage errors in under-4s. J Pediatr (Rio J) [Internet]. 2012 [acesso em: 30 jun 2013];88(4):297-302. Disponível em: http://dx.doi.org/10.2223/JPED.2189. 14. Winston FK, Chen IG, Smith R, Elliott MR. Parent driver characteristics associated with sub-optimal restraint of child passengers. Traffic Inj Prev [Internet]. 2006 [acesso em: 30 jun 2013];7(4):373-80. Disponível em:

http://dx.doi.org/10.1080/15389580600789143.

Artigo recebido em 18/04/2012.

Aprovado para publicação em 06/12/2012.

Artigo publicado em 30/06/2013. 